\title{
Speech Recognition dengan Hidden Markov Model untuk Pengenalan dan Pelafalan Huruf Hijaiyah
}

\author{
Qothrun Nada ${ }^{1}$, Cahya Ridhuandi $^{1}$, Puji Santoso ${ }^{1}$, Dwi Apriyanto ${ }^{1}$ \\ ${ }^{1}$ Program Studi Teknik Informatika, Fakultas Teknologi Informasi, Perbanas Institute-Jakarta, \\ Jl.Perbanas, Karet Kuningan, Setiabudi, Jakarta Selatan 12940, Indonesia \\ Penulis untuk Korespondensi/E-mail: qothrunnada197@gmail.com
}

Abstrak - Pelajaran utama dalam membaca Al Qur'an adalah mengenali dan melafalkan huruf-huruf Hijaiyah. Beberapa fakta menunjukkan bahwa pengucapan yang salah dapat memengaruhi makna secara harafiah. Speech Recognition, sebagai teknologi saat ini, dapat digunakan untuk memeriksa kesalahan dalam melafalkan surat Hijaiyah melalui pengenalan suara atau ucapan. Itu dapat dikonversi menjadi data yang dapat dipahami oleh sistem. Tujuan dari penelitian ini adalah untuk menerapkan Speech Recognition dengan Hidden Markov Model untuk pelafalan huruf Hijaiyah ketika belajar membaca Alquran. Pengenalan ucapan dan Model Hidden Markov dilakukan untuk mengembangkan sistem antar muka mesin berbasis suara. Dalam penelitian ini juga menggunakan metode Fast Fourier Transform (FFT) untuk mengekstraksi sifat. Hidden Markov Model (HMM) yang digunakan dalam proses pelatihan. Juga, menghasilkan karakteristik khusus untuk setiap huruf Hijaiyah. Dan kemudian, Euclidean Distance (ED) untuk klasifikasi akhir dalam mendeteksi pelafalan huruf Hijaiyah. Hasil penelitian menunjukkan bahwa hasil tes huruf Hijaiyah pada tingkat akurasi yang sama adalah 100\%, sedangkan pengujian huruf yang berbeda adalah 54,6\%. Dengan demikian, penelitian ini akan memberikan kontribusi kepada siswa yang sedang belajar membaca Al-Qur'an untuk dapat mengenali dan melafalkan huruf-huruf Hijaiyah.

Abstract - The main lesson in reading the Al Qur'an is recognizing and reciting the letters Hijaiyah. Some facts show that incorrect pronunciation can affect meaning literally. Speech Recognition, as the current technology, can be used to check the mistakes in pronouncing the Hijaiyah's letter through recognizing the voice or speech. It can convert into data that can be understood by the system. The purpose of this study is to implement Speech Recognition with Hidden Markov Model for Hijaiyah letter pronunciation when learning to read the Qur'an. Speech recognition and Hidden Markov Models were carried out to develop a sound-based machine interface system. In this study also used the Fast Fourier Transform (FFT) method to extract traits. Hidden Markov Model (HMM) used in the training process. Also, produced the especially characteristics for each letter of Hijaiyah. And then, Euclidean Distance (ED) for the final classification in detecting Hijaiyah letter pronunciation. The results of the study show that the results of the Hijaiyah letter test on the same level of accuracy are $100 \%$, while the testing of different letters is $\mathbf{5 4 . 6 \%}$. Thus, this study will contribute to students who are learning to read Al-Qur'an to be able to recognize and recite the Hijaiyah letters.

Keywords - Speech Recognition, Hidden Markov Model, Recognizing, Reciting, Letter Hijaiyah

\section{PENDAHULUAN}

$\mathrm{H}$ uruf hijaiyah adalah salah satu jenis huruf yang khas yang ditampilkan dalam Al-Qur'an AlQu'ran memang disusun menggunakan huruf hijaiyah dengan makhraj yang berbeda sekaligus mengisyaratkan bahwa Al-Qur'an diturunkan menggunakan bahasa Arab [1]. Seseorang perlu belajar huruf hijaiyah beserta ilmu tajwid untuk dapat membaca dan memahami Al-Quran. Belajar huruf hijaiyah merupakan tahap paling awal dalam proses pembelajaran Al-Quran. Pada perkembangan zaman banyak anak-anak, remaja, maupun orang dewasa yang tidak dapat membaca Al-Quran karena belum bisa melafalkan huruf Hijaiyah tersebut dengan benar dan mempelajari hukum bacaan Tajwid. Dalam proses pembelajaran tersebut tentunya masih diperlukan pembimbing khusus/ahli 
tajwid yang sudah mampu membaca Al-Quran untuk mengenalkan dan mengajarkan huruf hijaiyah pada pembelajar. Atas dasar permasalahan ini penulis mencoba membuat sistem yang mampu menggantikan peran pembimbing sebagai korektor pembelajar dalam pembacaan huruf hijaiyah.

Speech recognition adalah alat yang ampuh untuk pertukaran informasi menggunakan sinyal akustik [2]. Selain itu, speech recognition merupakan proses identifikasi suara berdasarkan kata yang diucapkan. Parameter yang dibandingkan ialah tingkat penekanan suara yang kemudian akan dicocokkan dengan template database yang tersedia. Sistem pengenalan suara berdasarkan orang yang berbicara inilah yang dinamakan speaker recognition. Speech recognition (juga dikenal sebagai pengenalan suara otomatis, pengenalan komputer pidato, pidato ke teks) mengkonversi kata yang diucapkan dengan teks. Para "Voice recognition" istilah kadang-kadang digunakan untuk merujuk pada sistem pengenalan yang harus dilatih untuk pembicara tertentu seperti halnya bagi sebagian besar perangkat lunak pengenal desktop. Menyadari pembicara dapat menyederhanakan tugas menerjemahkan pidato. Speech recognition adalah solusi yang lebih luas yang mengacu pada teknologi yang dapat mengenali pidato tanpa ditargetkan pada satu pembicara seperti panggilan sistem yang dapat mengenali suara sewenang-wenangnya [3].

Hidden Markov Model (HMM) merupakan model statistik dimana suatu sistem yang dimodelkan diasumsikan sebagai markov proses dengan kondisi yang tidak terobservasi. Suatu HMM dapat dianggap sebagai jaringan Bayesian dinamis yang sederhana atau 'simplest dynamic bayesian network' [4]. Dalam Markov Model biasa, setiap keadaan dapat terlihat langsung oleh pengamat. Oleh karena itu, kemungkinan dari transisi antar kondisi menjadi satu-satunya parameter teramati. Dalam HMM, keadaan tidak terlihat secara langsung. Tetapi output yang bergantung terhadap keadaan tersebut terlihat. Setiap kondisi memiliki distribusi kemungkinan disetiap output yang mungkin. Oleh karena itu, urutan langkah yang dibuat oleh HMM memberikan suatu informasi tentang urutan dari keadaan. Perlu dipahami, bahwa sifat hidden 'tersembunyi' menunjuk kepada kondisi langkah yang dilewati model, bukan kepada parameter dari model tersebut. Walaupun parameter model diketahui, model tersebut tetap tersembunyi. Hidden Markov Model dapat digunakan untuk aplikasi dibidang temporal pattern recognition 'pengenalan pola temporal', seperti pengenalan suara, tulisan, gestur, bioinformatika, kompresi kalimat, computer vision, ekonomi, finansial, dan pengenalan not balok. Adapun ciri- ciri yang terdapat pada Hidden Markov Model, yaitu: Pertama, observasi diketahui tetapi urutan keadaan (state) tidak diketahui sehingga disebut 'hidden' (tersembunyi). Kedua, observasi adalah fungsi probabilitas keadaan, dan Ketiga, perpindahan keadaan adalah dalam bentuk probabilitas [5].

Fast Fourier Transform (FFT) adalah metode yang sangat efisien untuk menghitung koefisien dari Fourier diskrit ke suatu finite sekuen dari data yang komplek [6]. Karena substansi waktu yang tersimpan lebih dari pada metoda konvensional, fast fourier transform merupakan aplikasi temuan yang penting didalam sejumlah bidang yang berbeda seperti analisis spectrum, speech and optical signal processing, design filter digital, pemfilteran dan analisa korelasi. Algoritma FFT berdasarkan atas prinsip pokok dekomposisi perhitungan Discrete Fourier Transform (DFT) dari suatu sekuen sepanjang N kedalam transformasi diskrit Fourier secara berturut-turut lebih kecil. Discrete Fourier Transformasi (DFT) adalah deretan yang terdefinisi pada kawasan frekuensi - diskrit yang merepresentasikan Transformasi Fourier terhadap suatu deretan terhingga (Finite Duration Sequence). Cara prinsip ini diterapkan memimpin ke arah suatu variasi dari algortima yang berbeda, dimana semuanya memperbandingkan peningkatan kecepatan perhitungan.

Euclidean Distance (ED) adalah perhitungan jarak dari 2 buah titik dalam Euclidean space [7]. Transformasi jarak berdasarkan Euclidean Distance (ED menurut studi tersebut ini disebut Euclidean Distance Transform/EDT). Ini telah banyak digunakan dalam metode numerik dalam pengenalan pola, visi komputer, analisis gambar, fisika dan matematika terapan. Euclidean Distance (ED) adalah perhitungan jarak dari 2 buah titik dalam Euclidean space. Euclidean space diperkenalkan oleh Euclid, seorang matematikawan dari Yunani sekitar tahun 300 SM, untuk mempelajari hubungan antara sudut dan jarak. Eucluidean ini berkaitan dengan teorema Phytagoras dan biasanya diterapkan pada 1, 2, dan 3 dimensi. Tapi juga sederhana jika diterapkan pada dimensi yang lebih tinggi.

Penelitian terkait pengenalan dan pelafalan huruf Hijaiyah sendiri pun masih sangat sedikit. Beberapa peneliti sebelumnya, seperti Shinwani membuat rancang bangun aplikasi Voice Translator Berbasis Android Menggunakan Hidden Markov Model [5]. 
Sedangkan, Gales dan Young melakukan penelitian terkait hal penerapan Hidden Markov Model dalam speech recognition. Dimana penelitian tersebut memiliki tujuan menyajikan arsitektur inti sistem Large Vocabulary Continuous Speech Recognition (LVCSR) berbasis Hidden Markov Model dan kemudian menggambarkan berbagai penyempurnaan yang diperlukan untuk mencapai kinerja canggih [8]. Penelitian yang berisi sebuah tinjauan oleh Sharma juga terkait Speech recognition dengan Hidden Markov Model [9]. Penelitian terkait pelafalan huruf hijaiyah dengan HMM dilakukan oleh beberapa peneliti. Peneliti Prasetyo dan Wisesty membuat suatu algoritma pengenalan ucapan Huruf Hijaiyah bertanda baca dengan Linear Predictive Coding (LPC) dan Hidden Markov Model $(H M M)$ [10], sedangkan Fauzi dkk meneliti tentang pengenalan ucapan Huruf Hijaiyah menggunakan Mel Frequency Cepstral Coefficients (MFCC) dan Hidden Markov Model (HMM) [11].

Penelitian ini berbeda dengan beberapa penelitian sebelumnya tersebut. Perbedaan tersebut terletak pada tujuan digunakannya Speech recognition dengan Hidden Markov Model serta metode lainnya yang mendukung dari tujuan penelitian. Pada penelitian ini bertujuan membuat sebuah sistem yang dapat pengenalan dan pelafalan huruf Hijaiyah melalui perekaman suara. Pada penelitian penerapaan Speech recognition ini akan menerapkan metode Fast Fourier Transform untuk mengubah sinyal kontinyu (data suara) menjadi sinyal diskrit (nilai matriks), yang kemudian sinyal diksrit tersebut akan diproses ke dalam Hidden Markov Model sebagai metode ramalan dalam membaca huruf Hijaiyah dengan ilmu Tajwid Mad Thobi'i berharokat Fathah, sehingga dapat menghasilkan data latih sebagai acuan yang dapat dibandingkan dengan data uji. Setelah itu menggunakan rumus jarak (distance) Euclidean Distance untuk klasifikasi akhir (benar atau salah cara membaca huruf Hijaiyah menggunakan ilmu Tajwid Mad Thobi'i berharokat Fathah) suara yang diuji. Hasil penelitian akan menunjukkan tingkat akurasi pengujian pada huruf yang sama dan pada pengujian huruf berbeda.

Diharapkan bahwa penelitian ini akan memberikan kontribusi kepada siswa yang sedang belajar membaca Al-Qur'an untuk dapat mengenali dan melafalkan huruf-huruf Hijaiyah.

\section{METODE}

\section{Desain, tempat dan waktu}

Penelitian ini merupakan penelitian eksperimen dalam bentuk Single Subject Research (SSR). Penelitian eksperimen merupakan penelitian yang dimaksud untuk mengetahui ada tidaknya akibat dari sesuatu yang dikenakan pada subjek yang diselidiki [12]. Penelitian ini di lakukan di Lab. IPRG (Institute Perbanas Research Group), Perbanas Institute dan dilaksanakan pada tanggal 11 Agustus 2017 - 25 September 2018.

\section{Jumlah dan cara pengambilan subjek}

Dalam penelitian ini dibutuhkan alat dan bahan sehingga penelitian berjalan dengan lancar. Misalnya alat perekaman suara untuk mendapatkan data audio, serta beberapa software yang terkait.

\section{Jenis dan cara pengumpulan data}

Permasalahan utama yang akan diselesaikan pada penelitian ini adalah bagaimana cara membaca huruf hijaiyah dengan ilmu tajwid mad thobi'i berharokat fathah dengan benar. Untuk menyelesaikan permasalah tersebut menggunakan beberapa prosedur atau tahapan serta bagaimana pengumpulan data untuk penelitian.

\section{Tahap 1- Proses Sampling}

Proses sampling merupakan proses perubahan waktu yang berjalan diubah kedalam bentuk diskrit. Selanjutnya, frekuensi dari waktu ini biasanya disebut dengan sampling rate atau frekuensi sampling. Hasilnya berupa data matriks, dengan melalui beberapa tahapan pra-proses. Langkah pertama yang harus dilakukan adalah pembuatan data audio melalui proses perekaman. Adapun output dari proses ini adalah file wav, dengan mengambil sampel tiap 1 detik dengan frekuensi sampling sebesar $48000 \mathrm{~Hz}$ (48000 sampel perdetik).

\section{Tahap 2 - Ekstrak Ciri (FFT)}

Setelah proses sampling dilakukan, FFT yang berguna untuk menyederhanakan pola suara dengan mengambil nilai penting dari suara tersebut dan mengubah tipe data suara menjadi matriks agar memudahkan untuk proses analisa. Matriks tersebut yang nantinya akan diproses dan dipakai untuk klasifikasi $H M M$ dan mencari jarak terkecil untuk menentukan hasil akhir. 
Adapun penjelasan proses $F F T$ dapat ditunjukkan dari flowchart pada Gambar 1.

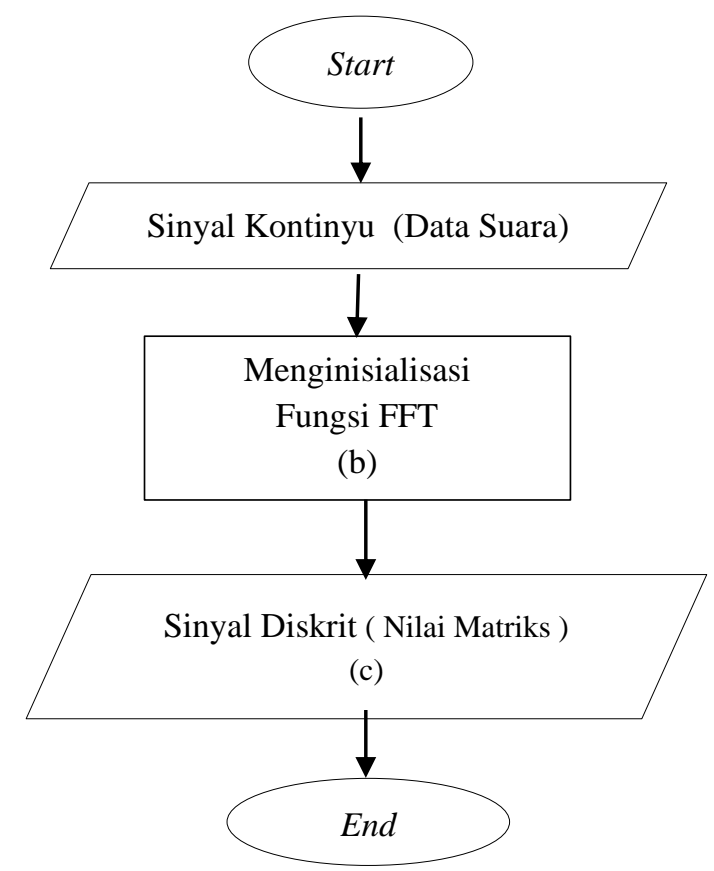

Gambar 1. Proses Fast Fourier Transform (FFT)

\section{Sinyal Kontinyu (Data Suara)}

Awal dari proses $F F T$ adalah memasukkan rekaman suara yang berupa sinyal kontinyu. Sinyal kontinyu merupakan sinyal yang memiliki nilai pada keseluruhan waktu dan sinyal ini bisa didapatkan dari proses rekaman. Seperti pada Gambar 2.

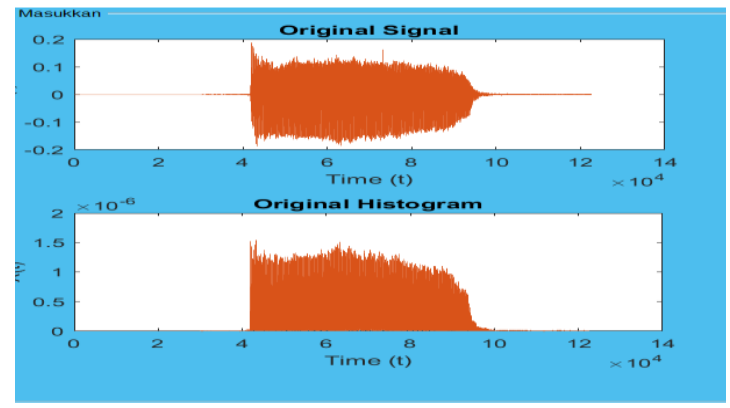

Gambar 2. Sinyal Kontinyu Suara Alif (Sumber Hasil Penelitian)

\section{Menginisialisasi Fungsi FFT.}

Langkah awal adalah mendapatkan nilai amplitudo, frekuensi, frame rate dan panjang $\mathrm{n}$ dari file audio. Selanjutnya sinyal akan dipecah menjadi dua bagian yang masing-masing terdiri dari $(\mathrm{n} / 2)$ - titik, yaitu satu adalah kumpulan dari nilai-nilai berindeks genap dan satu kumpulan lagi dari nilai-nilai berindeks ganjil.

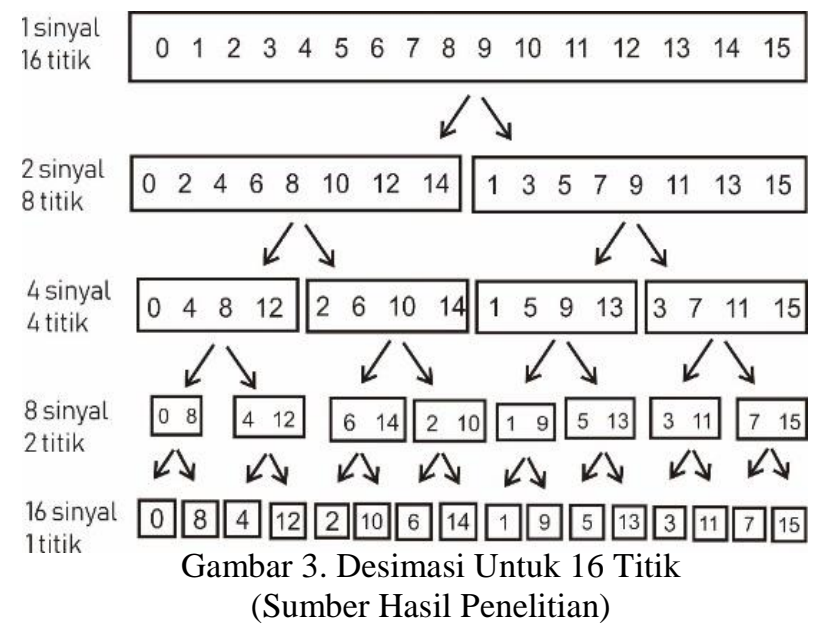

Gambar 3, merupakan perhitungan untuk $\mathrm{n}=16$ adalah ${ }^{2} \log 16=4$ tingkat (dihitung sampai mendapat 1 titik). Setelah dilakukan proses ganjil genap, maka langkah selanjutnya perhitungan nilai ganjil genap menjadi koefisien sinus cosinus sebagai nilai FFT. Dengan menggunakan rumus FFT:

$x(k)=\sum_{n=0}^{N-1} x(n) \sin \left(\frac{2 \pi k n}{N}\right)+j \sum_{n=0}^{N-1} x(n) \cos \left(\frac{2 \pi k n}{N}\right)$

dimana:

$\mathrm{x}$ (n) adalah koefisien sinus dan cosinus pada $2 \pi \mathrm{k} / \mathrm{N}$.

$\mathrm{k} \quad$ adalah indeks dri frekuensi pada frekuensi ke-N, dan $n$ adalah indeks waktu.

$\mathrm{x}(\mathrm{k})$ adalah nilai dari spektrum ke-k (domain frekuensi).

$\mathrm{x}(\mathrm{n}) \quad$ adalah nilai sinyal pada domain waktu.

\section{Sinyal Frekuensi Diskrit (Nilai Matriks)}

Ini merupakan hasil akhir dari proses FFT. Hasil akhir yang berupa sinyal frekuensi diksrit atau berupa nilai matriks yang nantinya akan dijadikan perhitungan untuk perhitungan rumus hidden markov model dan perhitungan jarak menggunakan Euclidean Distance.

Ini merupakan hasil akhir dari proses FFT. Hasil akhir yang berupa sinyal frekuensi diksrit atau berupa nilai matriks yang nantinya akan dijadikan perhitungan untuk perhitungan rumus hidden markov model dan perhitungan jarak menggunakan Eculidean distance. Gambar 3 merupakan hasil sinyal original dari data uji Alif diubah menjadi sinyal FFT. 


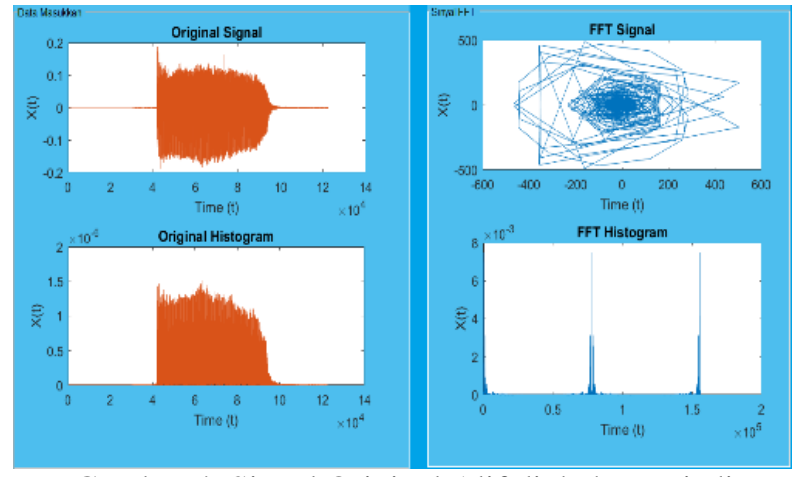

Gambar 4. Sinyal Original Alif diubah Menjadi Sinyal FFT (Hasil penelitian)

\section{Pencocokan Huruf Hijaiyah}

Data FFT yang telah didapat kemudian dilakukan proses pencocokan antar data uji dengan data latih yang telah disediakan. Pada proses ini menggunakan proses perhitungan hidden markov model dan perhitungan jarak Eculidean Distance (ED) untuk klasifikasi data uji. Dengan menghitung jarak dari 2 buah frekuensi yaitu jarak data uji terhadap data latih yang didapat dari proses $H M M$.

Penggunaan rumus Hidden Markov Model dijelaskan dengan cara mendefinisikan $N$, yaitu jumlah keadaan tersembunyi (hidden state) meliputi data pola/jarak (data uji) yang menyerupai atau mendekati pola/jarak aslinya (data latih).

Definisikan $M$, yaitu jumlah keadaan terobservasi yang didapat dari data diskrit audio. Probabilitas transisi, yaitu:

$A \_i j=\left\{a \_i j\right\}=P\left(X \_(t+1)=q \_j \mid X \_t=q \_i\right)$ untuk setiap $1 \leq i \leq N$ dan $1 \leq j \leq N$.

Dengan kata lain $A$, didapatkan dengan memperhatikan perpindahan keadaan yang tersembunyi (hidden state) dan $A$ matriks berukuran $N x N$.

Probabilitas observasi $\quad B=b \_i\left(v \_k\right)=P\left(O \_t=v_{-} k\right.$ $\left.\mid X_{-} t=q \_i\right), 1 \leq i \leq N$ dan $1 \leq k \leq M$.

Dengan kata lain $B$ didapatkan dengan mengamati nilai audio atau suara yang terjadi (observed state) dan $B$ matriks berukuran $N x M$.

Distribusi keadaan awal: $\pi=\left\{\pi \_i\right\}, \pi \_i=P\left(X \_0=q \_i\right)$ untuk $1 \leq i \leq N, 0 \leq \pi \_i \leq 1$.

Distribusi ini merupakan inisialisasi bahwa keadaan awal berdasarkan nilai matriks observasi. Dimana nilai dari $1 \leq i \leq N$ berupa data yang ada dan tidak sama dengan nol. Dan nilai $\pi$ merupakan nilai peluang awal. Hasil dari tiap-tiap peluang tadi kemudian di jumlahkan dan diambil nilai rataratanya untuk menghasilkan data latih acuan. Data latih acuan ini nantinya akan dibandingkan dengan data uji menggunakan klasifikasi jarak Eculidean distance. Untuk perhitungan kedekatan antara benar atau salahnya suatu suara adalah dengan pegujian jarak berdasarkan nilai threshold yang telah di tentukan.

Dan rumus perhitungan jarak menggunakan Euclidean Distance, sebagai berikut:

$\operatorname{dist}(x, y)=\sqrt{\sum_{i=1}^{n}\left(x_{i}-y_{i}\right)^{2}}$

dimana:

$\mathrm{n}=$ banyaknya sampling data

$\mathrm{xi}=$ matriks data latih $H M M$ (nilai data uji)

yi $=$ matriks data uji (nilai data latih)

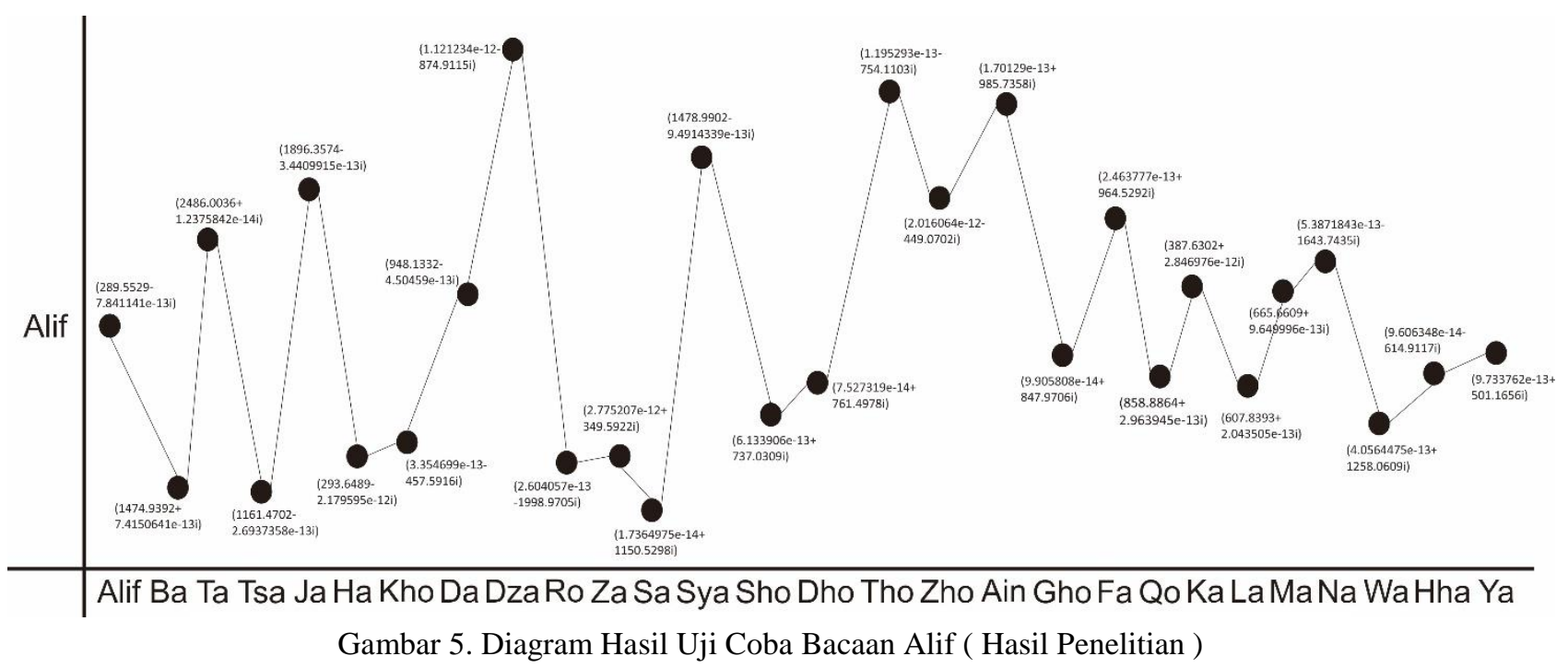


Setelah jarak diketahui, maka akan dibandingkan nilai threshold atau nilai batas ambang yang sudah ditentukan. Nilai threshold didapat dari nilai tertinggi dari proses uji coba data latih dengan data uji.

Sebagai contoh uji coba bacaan alif, Jika nilai data uji yang dimasukkan kurang dari nilai threshold yang ditentukan, maka sistem akan mendeteksi sebagai bacaan alif yang benar. Dan sebaliknya, jika nilai data uji yang dimasukkan lebih besar dari nilai threshold yang ditentukan, maka sistem akan mendeteksi sebagai bacaan alif yang salah.

Diagram hasil uji coba bacaan alif dengan huruf yang berbeda ditunjukkan seperti pada Gambar 4 .

Diketahui bahwa threshold suara Alif adalah 289.5529-7.841141e-13i. Jika dibandingkan dengan data suara dza maka sistem akan mendeteksi sebagai bacaan Alif yang salah, karena threshold Alif lebih besar daripada jarak bacaan Dza terhadap data alif.

Namun, jika suara alif dibandingkan dengan data suara Ba maka sistem akan mendeteksi sebagai bacaan Alif yang benar, karena threshold Alif lebih kecil daripada jarak bacaan Ba terhadap data alif itu sendiri.

Terdapat juga faktor yang menyebabkan tidak sesuainya pernyataan dalam sistem tersebut yaitu perbedaan versi software untuk merekam suara sehingga menyebabkan suara menjadi berbeda.

\section{HASIL DAN PEMBAHASAN}

\section{Hasil Uji Tingkat Akurasi}

Pada bagian ini akan dijelaskan mengenai serangkaian uji coba tingkat akurasi kebenaran dengan huruf hijaiyah yang sama dan dengan huruf berbeda.

Pada uji coba tingkat akurasi kebenaran dengan huruf Hijaiyah yang sama maka hasil akurasinya rata-rata adalah $100 \%$. Hasil ini ditunjukkan pada Tabel 1.

Pengujian berikut untuk uji Tingkat akurasi kebenaran dengan Huruf Hijaiyah yang berbeda, hasilnya ditunjukkan pada Tabel 2, dalam penelitian ini.
Pada uji coba tingkat akurasi kebenaran dengan huruf Hijaiyah yang berbeda maka hasil akurasinya rata-rata adalah $54,6 \%$.

\section{Pembahasan}

Dapat diketahui dari Tabel 2, bahwa tingkat akurasi dari pengujian huruf terhadap huruf yang berbeda adalah 54,6\%. Dikarenakan nilai Threshold dari suatu huruf lebih kecil daripada jarak bacaan antara data uji dengan data yang dipilih.

Terdapat juga faktor yang menyebabkan ketidaksesuaian dalam sistem tersebut yaitu perbedaan versi software untuk merekam suara sehingga menyebabkan suara menjadi berbeda.

Hal yang menarik dalam penelitian penerapan Speech Recognition dengan Hidden Markov Model untuk pelafalan huruf Hijaiyah disini adalah dengan menambahkan Proses Fast Fourier Transform (FFT) yang berfungsi untuk menyederhanakan pola suara dengan mengambil nilai penting dari suara tersebut dan mengubah tipe data suara menjadi nilai matriks agar memudahkan untuk proses selanjutnya.

Penggunaan Fast Fourier Transform (FFT) pada feature extraction dapat diintegrasikan dengan Hidden Markov Model (HMM) sebagai model pengenalannya untuk mengenali suara huruf hijaiyah berdasarkan mad thobi'i berharokat fathah

Disamping itu digunakannya rumus jarak (distance) Euclidean Distance untuk klasifikasi akhir (benar atau salah cara membaca huruf Hijaiyah menggunakan ilmu Tajwid Mad Thobi'i berharokat Fathah) suara yang diuji.

Tabel 1. Hasil Pengujian dengan Huruf Sama

\begin{tabular}{llc}
\hline Huruf & \multicolumn{1}{c}{ Nilai Treshold } & $\begin{array}{c}\text { Hasil } \\
\text { Akurasi }\end{array}$ \\
\hline Alif & $289.5529-7.841141 \mathrm{e}-13 \mathrm{i}$ & $100 \%$ \\
\hline $\mathrm{Ba}$ & $2038.6804-3.86242 \mathrm{e}-13 \mathrm{i}$ & $100 \%$ \\
\hline $\mathrm{Ta}$ & $938.677-5.223037 \mathrm{e}-16 \mathrm{i}$ & $100 \%$ \\
\hline Tsa & $1318.0358-1.0779922 \mathrm{e}-13 \mathrm{i}$ & $100 \%$ \\
\hline $\mathrm{Ja}$ & $1400.4281-6.3470442 \mathrm{e}-14 \mathrm{i}$ & $100 \%$ \\
\hline $\mathrm{Ha}$ & $635.3653+1.846209 \mathrm{e}-14 \mathrm{i}$ & $100 \%$ \\
\hline $\mathrm{Kho}$ & $1302.8386-1.2256727 \mathrm{e}-13 \mathrm{i}$ & $100 \%$ \\
\hline $\mathrm{Da}$ & $386.9596-5.464704 \mathrm{e}-14 \mathrm{i}$ & $100 \%$ \\
\hline
\end{tabular}




\begin{tabular}{|c|c|c|}
\hline Huruf & Nilai Treshold & $\begin{array}{c}\text { Hasil } \\
\text { Akurasi }\end{array}$ \\
\hline Dza & $6.290454 \mathrm{e}-13-434.8908 \mathrm{i}$ & $100 \%$ \\
\hline $\mathrm{Ra}$ & $2.9766519 \mathrm{e}-13-1529.9103 \mathrm{i}$ & $100 \%$ \\
\hline $\mathrm{Za}$ & $1177.1488-4.1681389 \mathrm{e}-13 \mathrm{i}$ & $100 \%$ \\
\hline $\mathrm{Sa}$ & $1257.0077+5.0520579 \mathrm{e}-14 \mathrm{i}$ & $100 \%$ \\
\hline Sya & $6.7638477 \mathrm{e}-13+1359.0637 \mathrm{i}$ & $100 \%$ \\
\hline Sho & $915.5667-5.13073 \mathrm{e}-14 \mathrm{i}$ & $100 \%$ \\
\hline Dho & $105.4895-9.112521 \mathrm{e}-14 \mathrm{i}$ & $100 \%$ \\
\hline Tho & $105.4895-9.112521 \mathrm{e}-14 \mathrm{i}$ & $100 \%$ \\
\hline Zho & $5.676318 \mathrm{e}-12-1428.2946 \mathrm{i}$ & $100 \%$ \\
\hline Ain & $1.1793852 \mathrm{e}-13+1116.3564 \mathrm{i}$ & $100 \%$ \\
\hline Gha & $415.5447+5.66176 \mathrm{e}-13 \mathrm{i}$ & $100 \%$ \\
\hline $\mathrm{Fa}$ & $1.952042 \mathrm{e}-13-800.6062 \mathrm{i}$ & $100 \%$ \\
\hline Qo & $1122.3084-2.8457188 \mathrm{e}-13 \mathrm{i}$ & $100 \%$ \\
\hline $\mathrm{Ka}$ & $552.5721+1.704794 \mathrm{e}-13 \mathrm{i}$ & $100 \%$ \\
\hline $\mathrm{La}$ & $1226.1875-1.7176381 \mathrm{e}-13 \mathrm{i}$ & $100 \%$ \\
\hline $\mathrm{Ma}$ & $1226.1875-1.7176381 \mathrm{e}-13 \mathrm{i}$ & $100 \%$ \\
\hline $\mathrm{Na}$ & $3.1083789 \mathrm{e}-13+1662.0113 \mathrm{i}$ & $100 \%$ \\
\hline $\mathrm{Wa}$ & $1323.5863-3.7478888 \mathrm{e}-14 \mathrm{i}$ & $100 \%$ \\
\hline Hha & $7.713669 \mathrm{e}-13-737.2207 \mathrm{i}$ & $100 \%$ \\
\hline Ya & $296.3482+1.0513 \mathrm{e}-12 \mathrm{i}$ & $100 \%$ \\
\hline
\end{tabular}

\begin{tabular}{|c|c|c|}
\hline Huruf & Nilai Treshold & $\begin{array}{c}\text { Hasil } \\
\text { Akurasi }\end{array}$ \\
\hline Ro & $2.9766519 \mathrm{e}-13-1529.9103 \mathrm{i}$ & $32 \%$ \\
\hline $\mathrm{Za}$ & $1177.1488-4.1681389 \mathrm{e}-13 \mathrm{i}$ & $61 \%$ \\
\hline $\mathrm{Sa}$ & $1257.0077+5.0520579 \mathrm{e}-14 \mathrm{i}$ & $50 \%$ \\
\hline Sya & $6.7638477 \mathrm{e}-13+1359.0637 \mathrm{i}$ & $39 \%$ \\
\hline Sho & $915.5667-5.13073 \mathrm{e}-14 \mathrm{i}$ & $68 \%$ \\
\hline Dho & $105.4895-9.112521 \mathrm{e}-14 \mathrm{i}$ & $32 \%$ \\
\hline Tho & $105.4895-9.112521 \mathrm{e}-14 \mathrm{i}$ & $46 \%$ \\
\hline Zho & $5.676318 \mathrm{e}-12-1428.2946 \mathrm{i}$ & $43 \%$ \\
\hline Ain & $1.1793852 \mathrm{e}-13+1116.3564 \mathrm{i}$ & $61 \%$ \\
\hline Gho & $415.5447+5.66176 \mathrm{e}-13 \mathrm{i}$ & $57 \%$ \\
\hline $\mathrm{Fa}$ & $1.952042 \mathrm{e}-13-800.6062 \mathrm{i}$ & $32 \%$ \\
\hline Qo & $1122.3084-2.8457188 \mathrm{e}-13 \mathrm{i}$ & $54 \%$ \\
\hline $\mathrm{Ka}$ & $552.5721+1.704794 \mathrm{e}-13 \mathrm{i}$ & $46 \%$ \\
\hline $\mathrm{La}$ & $1226.1875-1.7176381 \mathrm{e}-13 \mathrm{i}$ & $39 \%$ \\
\hline $\mathrm{Ma}$ & $1226.1875-1.7176381 \mathrm{e}-13 \mathrm{i}$ & $71 \%$ \\
\hline $\mathrm{Na}$ & $3.1083789 \mathrm{e}-13+1662.0113 \mathrm{i}$ & $46 \%$ \\
\hline $\mathrm{Wa}$ & $1323.5863-3.7478888 \mathrm{e}-14 \mathrm{i}$ & $75 \%$ \\
\hline Hha & $7.713669 \mathrm{e}-13-737.2207 \mathrm{i}$ & $39 \%$ \\
\hline $\mathrm{Ya}$ & $296.3482+1.0513 \mathrm{e}-12 \mathrm{i}$ & $43 \%$ \\
\hline
\end{tabular}

Sumber: Hasil Penelitian

Tabel 2. Hasil Pengujian dengan Huruf Berbeda

\begin{tabular}{lcc}
\hline Huruf & Nilai Treshold & $\begin{array}{c}\text { Hasil } \\
\text { Akurasi }\end{array}$ \\
\hline Alif & $289.5529-7.841141 \mathrm{e}-13 \mathrm{i}$ & $50 \%$ \\
\hline $\mathrm{Ba}$ & $2038.6804-3.86242 \mathrm{e}-13 \mathrm{i}$ & $14 \%$ \\
\hline $\mathrm{Ta}$ & $938.677-5.223037 \mathrm{e}-16 \mathrm{i}$ & $32 \%$ \\
\hline Tsa & $1318.0358-1.0779922 \mathrm{e}-13 \mathrm{i}$ & $50 \%$ \\
\hline Ja & $1400.4281-6.3470442 \mathrm{e}-14 \mathrm{i}$ & $28 \%$ \\
\hline Ha & $635.3653+1.846209 \mathrm{e}-14 \mathrm{i}$ & $32 \%$ \\
\hline Kho & $1302.8386-1.2256727 \mathrm{e}-13 \mathrm{i}$ & $75 \%$ \\
\hline Da & $386.9596-5.464704 \mathrm{e}-14 \mathrm{i}$ & $35 \%$ \\
\hline Dza & $6.290454 \mathrm{e}-13-434.8908 \mathrm{i}$ & $61 \%$ \\
\end{tabular}

Sumber: Hasil Penelitian

\section{KESIMPULAN}

Penelitian ini bertujuan untuk menerapkan Speech Recognition dengan Hidden Markov Model untuk pelafalan huruf Hijaiyah ketika belajar membaca Alquran. Selain penerapan Speech Recognition, maka dalam penelitian ini terdapat beberapa tahapan proses pengolahan sinyal untuk menghasilkan sebuah huruf hijaiyah, yaitu proses sampling, Fast Fourier Transform (FFT), Hidden Markov Model (HMM), dan Euclidean Distance (ED).

Hasil penelitian menunjukkan bahwa hasil pengujian kebenaran huruf Hijaiyah pada tingkat akurasi dengan huruf sama adalah $100 \%$, sedangkan pengujian huruf yang berbeda adalah 54,6\%. 
Sebagai rekomendasi penelitian dimasa mendatang agar dapat meningkatkan fungsionalitas aplikasi terapan ini, maka dengan menambahkan jumlah sampel data latih agar dapat lebih banyak ciri yang dapat diambil.

Selanjutnya, untuk meningkatkan hasil akurasi perlunya menggunakan rumus pendekatan jarak (distance) yang berbeda untuk klasifikasi akhir agar tingkat akurasi pengujian huruf hijaiyah terhadap huruf yang berbeda tingkat akurasinya semakin meningkat.

\section{UCAPAN TERIMA KASIH}

Penulis mengucapkan banyak terima kasih kepada Direktorat Penelitian dan Pengabdian kepada Masyarakat (P3M) Perbanas Institute Jakarta atas bantuan pendanaan dalam pelaksanaan penelitian ini.

Penulis juga mengucapkan terima kasih kepada Dekan Fakultas Teknologi Informasi dan Ketua Program Studi Teknik Informatika Perbanas Institute-Jakarta yang telah mendukung terselesaikannya penelitian ini.

\section{REFERENSI}

[1] D. Siswanti, Meningkatkan Kemampuan Membaca Huruf Hijaiyah Melalui Metode VAKT Dengan Media Plastisin Bagi Anak Tuna Grahita Ringan, Jurnal Ilmiah Pendidikan Khusus (E-JUPEKhu), Vol. 1, No. 3, pp. 122-133, 2012.

[2] R. S, Chavan \& G. S Sable, An Overview of Speech Recognition Using HMM, International Journal of Computer Science and Mobile Computing, Vol. 2, Issue. 6, pp.233 - 238, 2013.

[3] W. Kurniawan, Identifikasi Speech Recognition Manusia dengan Menggunakan Average Energy dan Silent Ratio Sebagai Feature Extraction Suara pada Komputer, Biospecies, Vol. 9, No. 1, pp. 1-6, 2016.
[4] H. Sujadi, I. Sopiandi, and A. Mutaqin, Sistem Pengolahan Suara Menggunakan Algoritma FFT (Fast Fourier Transform), Prosiding SINTAK, pp. 101-107, 2017.

[5] M. F. Shinwani, Rancang Bangun Aplikasi Voice Translator Berbasis Android Menggunakan Hidden Markov Model. 2016

[6] R. Y. Sipasulta, A. S. M. L. Stepen, \& S. R. U. A. Sompie, Simulasi Sistem Pengacak Sinyal Dengan Metode FFT ( Fast Fourier Transform . E-journal Teknik Elektro dan Komputer, pp. 1-9, 2014

[7] J.C Torelli., R.Fabbri., G. Travieso \& O.M Bruno. A High Performance 3-D Exact Euclidean Distance Transform Algorithm For Distributed Computing. International Journal of Pattern Recognition and Artificial Intelligence. Vol. 24, No. 6. Pp. 1-9, 2010.

[8] M. Gales and S Young. The Application of Hidden Markov Models in Speech Recognition. Foundations and Trends in Signal Processing. Vol. 1, No. 3 195-304, 2007

[9] S. Sharma. "Speech Recognition with Hidden Markov Model: A Review".International Journal of Scientific \& Engineering Research,Volume 6, Issue 11, November, 2015

[10] H.B Prasetyo dan U.N Wisesty. Algoritma Pengenalan Ucapan Huruf Hijaiyah Bertanda Baca Dengan Linear Predictive Coding (LPC) dan Hidden Markov Model (HMM). Conference Paper in Indonesia Symposium on Computing. September, 2016.

[11] R.M Fauzi, Adiwijaya, W. Maharani. Pengenalan Ucapan Huruf Hijaiyah Menggunakan Mel Frequency Cepstral Coefficients (MFCC) dan Hidden Markov Model (HMM). Tugas Akhir- Telkom University, 2013.

[12] S Arikunto. Manajemen Penelitian. Penerbit PT Rineka Cipta, 2003 